\title{
Early severe anemia as the first sign of cystic fibrosis
}

\author{
Melodie Olivia Loredana Rosa Aricò ${ }^{1} \cdot$ S. Ielo ${ }^{1}$ - L. Palma ${ }^{1}$ M. Maschio ${ }^{1}$. \\ L. Lubrano ${ }^{1}$ - A. Pietrobelli ${ }^{1}$ - D. Degani ${ }^{1}$ - C. D'Orazio ${ }^{1}$
}

Received: 18 April 2017 / Accepted: 20 August 2017 / Published online: 30 August 2017

(C) Springer-Verlag GmbH Germany 2017

\section{Dear Editor,}

Sismanlar et al. introduced that early severe anemia may be the first sign of cystic fibrosis (CF). Among their 231 patients with $\mathrm{CF}$, they identified 17 subjects with isolated severe anemia. CF patients with isolated anemia are younger, have a lower level of albumin, and prolonged PT/INR.

Recently, we coped an 82-day Italian male with insufficient growth and pallor. He was recently hospitalized because of bronchiolitis, followed by rotavirus enteritis. Moderate anemia $(8.7 \mathrm{~g} / \mathrm{dL})$ was interpreted as sideropenic and treated with oral supplementation.

On admission, he was extremely pale, with green, liquid stools. CBC showed RBC $2.12 \times 10^{12} / \mathrm{L}, \mathrm{Hb} 6.1 \mathrm{~g} / \mathrm{dL}, \mathrm{MCV}$ $92 \mathrm{fl}$. No signs of hemolysis or other common causes of anemia were found.

Anemia was treated with erythropoietin, with no success. Transfusion induced transient correction of anemia. A few days later, during an upper respiratory infection with diarrhea, albumin was $18.7 \mathrm{~g} / \mathrm{L}$; PT/INR 1.19. Sweat chloride test
(102-106 mmol/L) suggested $\mathrm{CF}$, confirmed by mutation analysis (Phe508del/2183AA $>$ G) despite negative screening for $\mathrm{CF}$ at birth.

Replacement therapy with pancreatic enzymes was started: anemia and stools normalized and the child gained weight.

We retrospectively reviewed our files and identified a 3 -month old girl with poor growth and severe dermatitis. CBC showed RBC $1.90 \times 10^{12} / \mathrm{L}, \mathrm{Hb} 5.5 \mathrm{~g} / \mathrm{dL}, \mathrm{MCV} 101 \mathrm{fL}$. Her brother was heterozygous for CF Phe508del mutation.

A single erythrocyte transfusion induced transient correction of anemia. Concurrent hypoalbuminemia $(16.2 \mathrm{~g} / \mathrm{L})$ was treated with replacement therapy. Since dermatitis progressed, fecal chymotrypsin level was found $1 \mathrm{U} / \mathrm{g}$. CF was diagnosed based on sweat chloride test (95-94 mmol/L) and evidence of Phe508del. Replacement therapy with pancreatic enzymes improved anemia and dermatitis.

Phe508del was present in 7/17 Sismanlar's patients and in our cases. This may suggest the need for a wider genotypephenotype evaluation.

D. Degani and C. D'Orazio equally contributed to this paper.

Communicated by Peter de Winter

Melodie Olivia Loredana Rosa Aricò

melodiearico@gmail.com

1 Pediatrics, University of Verona, Azienda Ospedaliera Universitaria

Verona, Verona, Italy 